\title{
Reciprocal Feedbacks between Education on Jewelry Design and Cultural Self-consciousness*
}

\author{
Wenwen Chen \\ Shanghai University of Engineering Science \\ Shanghai, China
}

\begin{abstract}
Cultural self-consciousness reflects people's judgment, pursuit and selection of value in cultures of their own and others. In Chinese universities, arts and ethics are integrated to a great extent in their education on jewelry design. Cultural self-consciousness enriches connotations of design education and jewelry education is important for development of cultural self-consciousness. Both of them are interdependent and develop through reciprocal feedbacks. This paper intends to trace the definition of "cultural selfconsciousness". Apart from the connections between jewelry design and cultural self-consciousness, it also discusses specific ways for developing cultural consciousness in education on jewelry design.
\end{abstract}

Keywords-jewelry design; cultural self-consciousness; reciprocal feedbacks; teaching model

\section{INTRODUCTION}

At present, jewelry design, jewelry appraisal and related programs are opened in more than 1,000 secondary schools and universities of China. However, the works highlighting cultural implications are not mainstream, on the grounds that knowledge about cultures remains to be further deepened in education about design. Mr. Fei Xiaotong, who is a famous sociologist, anthropologist and social activist, proposed the concept of "cultural self-consciousness" in 1997. Since its emergence in in humanities, it has aroused great concerns and controversies. This theory has not been discussed a lot in literature regarding artistic education. As a well-known Chinese scholar of artistic research and curator, Fei Dawei said that so-called "cross-cultural dialogues beyond cultural identities under the 'global context' are essentially equivalent to "internationalized languages" that use readily available Western modes of artistic thinking and languages, in order that arts can be internationally homogeneous [1]". Homogeneity is fatal to jewelry design and creation, reflecting a lack of cultural confidence. In following sections, attention will be paid to trace the definition of "cultural selfconsciousness". Apart from the connections between jewelry design and cultural self-consciousness, it also discusses specific ways for developing cultural self-consciousness in education on jewelry design.

*This paper is dedicated to the course construction project "Jewelry Design" in Shanghai University of Engineering Science. The project number is $\mathrm{k} 201712001$.

\section{IDENTIFYING CONCEPTS OF "CULTURE", "CONSCIOUSNESS" AND "CULTURAL SELF-CONSCIOUSNESS"}

\section{A. Definition of Culture}

"Culture", a common word used frequently, is utilized relatively widely no matter in the field of education, the academic circle or the domain of life. The concept of this word is also quite controversial. According to the definition of the Institute of Linguistics, Chinese Academy of Social Sciences, "cultures are aggregates of material and spiritual wealth created in the process of human social and historical development [2]". As a scholar, Yu Qiuyu interprets in his book titled What Are Cultures that "cultures are a kind of ecological communities that embody spiritual value and lifestyles". They foster collective personalities through accumulation and guidance [3]."Samuel Huntington and Larry Harrison, scholars of the United States, consider that if defined purely subjectively, cultures refer to values, attitudes, beliefs, orientations and people's common views in a society [4]." As a British scholar and father of anthropology, Edward Taylor points out that, "cultures, as a complex, comprise of knowledge, beliefs, arts, laws, ethics, custom, other capabilities and habits that people develop as social members [5]." Above all, cultures are spiritual wealth, values tacitly acknowledged by people and customary habits with moral implications.

\section{B. Definition of Jue (Consciousness) and Self- consciousness}

According to incomplete statistics, "consciousness" firstly appeared in languages of Buddhism. Jingying Huiyuan, a monk in Sui Dynasty, mentioned in Volume 20 of Da Cheng Yi Zhang that 'jue' in "juecha (notice)" is just like noticing thieves and 'jue' in 'juewu (realizing)' may be compared to awakening [6]." Here, "jue" has two meanings, namely "noticing" and "realizing". People who are sensible can discern bad things; those who are conscious are wise. All consciousness develops from personal "sensing" and "realization". Only if one discerns "bad things" of "herself or himself" and develops "wisdom" can he or she realizes "personal" "self-consciousness". Nevertheless, "selfconsciousness" is far from enough. In Buddhism, there are still three words about consciousness, namely "selfconsciousness", "enlightening others" and "development into Buddha". In terms of depth and span, "self-consciousness" is 
not only at the lowest level, but also fundamental for all "consciousness". Both "self-consciousness" and "enlightening others" are mental "consciousness". Only going beyond mental "awakening" can people keep their "consciousness" in line with their "actions" to a great extent. In other words, "development into Buddha" is the highest realm. Three of them are progressive [7].

Li Zhengtao, an education scholar, points out in his book Recreating a Spiritual Universe for Teachers" that "selfconsciousness is a basic orientation for growth and development of life, which highlights that development of people's life is primarily dominated by intrinsic motivations as a result of self-propelling, but not driven by external forces. In other words, such development is active and conscious, which has become a basic characteristic of people. Furthermore, he has pointed out that "consciousness" in "self-consciousness" refers to appreciation of personal and others' life, perception and understanding of the circumstances under which individuals live. [8]"

\section{Definition of Cultural Self-consciousness}

Mr. Fei Xiaotong put forward the theory of "cultural selfconsciousness" in light of problems with survival and development of ethnic minorities under the background of economic globalization at the second advanced seminar of sociology and anthropology. "Carrying forward beauty of oneself, admiring beauty of others, sharing beauty with each other and creating a world of universal brotherhood."which highly generalizes the concept of "cultural selfconsciousness". "Cultural self-consciousness" means that people from given cultures "know themselves" while understanding origins, development processes, characteristics and development orientations of their cultures. Knowing themselves is for enhancing autonomous abilities to transform cultures and occupying an independent position for them to adapt to new environment and cultural selection in a new era. Apparently, Mr. Fei has proposed the concept of cultural self-consciousness for particular time, space and environment. First of all, economy is globalized and cultures of different countries develop to be diverse, so people are supposed to understand and respect each other. Secondly, in consideration of cultural transformation, how to find out a common order for peaceful coexistence among diversified cultures is discussed. "Carrying forward beauty of oneself" implies that all cultures are equal, all countries and nations have their own cultural traits, cultural implications and unique merits. Therefore, people have to know about cultures of their nations and show confidence in the cultures. While reflecting that people shall be confident about cultures of their own nations, "admiring beauty of others" also places an emphasis upon respecting others' cultures, which is an acknowledgement. "Sharing beauty with each other" implies that nations exchange with each other about cultures and learn from each other to ultimately reach certain consensus and thereby create a "world of universal brotherhood". As a result, striving for harmony but not sameness is a principle and value orientation of cultural self-consciousness.

\section{RELATIONSHIPS BETWEEN CULTURAL SELF-} CONSCIOUSNESS AND EDUCATION ON JEWELRY DESIGN

In design programs of contemporary Chinese universities, jewelry design is a carrier and branch of the fashion circle, which not only reflects diversified ideologies, but also reveals contemporary artists' educational workers' and students' pondering upon contemporary social life and cultures. If cultural self-consciousness is said to embody people's judgment, pursuit and selection of value between cultures of themselves and others, education about design just plays cohesive and guiding roles. Closely integrating arts with ethics, it guides students to explore, understand and identify their cultures, in order to create more works with cultural implications and educate people with cultures. Cultural consciousness enriches connotations of design education and jewelry education is important for development of cultural consciousness. Both of them are interdependent and develop through reciprocal feedbacks.

\section{A. Promoting Development of Individuals and Stimulating Creative Behaviors}

In addition to imparting professional knowledge and skills, education about jewelry design also develops students' design consciousness and stimulates students' creativity, which is the foremost task of teaching jewelry design in universities. Creativity is not fostered overnight, while it is more inadvisable to comprehend creativity as seeking sameness and maintaining differences. Truly valuable innovations are deeply rooted in cultural self-consciousness. In university education, students are guided to understand specific historical and social cultures where they are. In this process, they are not only motivated to reflect upon cultures, but also impelled to explore cultures and generate power for promoting themselves in the course of such exploration. Each group has its own cultures, of which the formation process, distinguishing features and development trends drive self-awakening, self-reflection and self-creation of individuals in a group [10].

Such process of exploration, understanding and cognition are aggregated into design ideas, thus endowing works with cultural implications. However, cultural self-consciousness is neither "a restoration" nor "total westernization or total assimilation" [9]. This is just demonstrated by a collection of jewelry works named "Xixi" designed by Liu Chang from the Central Academy of Fine Arts, as shown in Fig 1. Considering electronic components as products of modern industrial civilization, she integrates symmetric and interconnected traditional Chinese auspicious patterns such as happiness, longevity, intertwined branches and love-birds. In addition, she utilizes technologies for printed circuit boards, including corrosion, carving, welding and paster to make gems dazzle like gems with light-emitting LED. Thus, it is clear that works with rich cultural implications have lasting charms. Reflections and stimulated innovative behaviors have activated personalized non-reproducible inspirations with the intensification of globalization. 


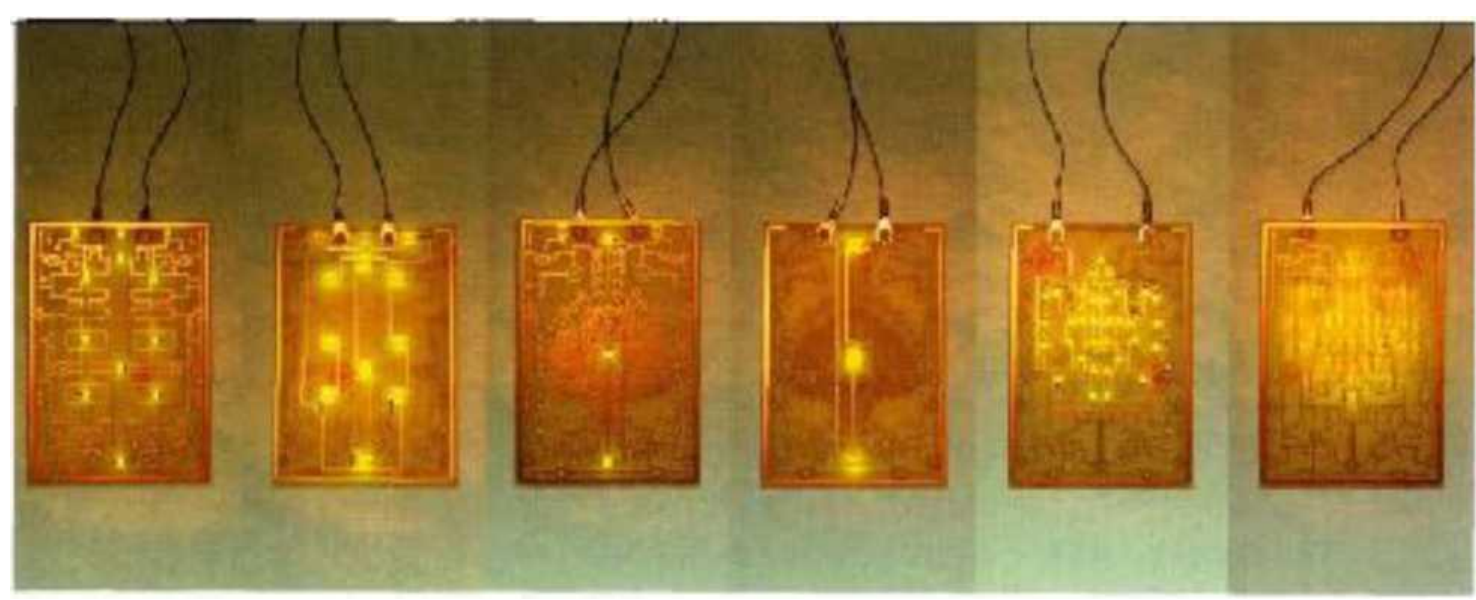

Fig. 1. "Xixi” Series Jewelry [11].

\section{B. Accumulating Collective Personalities and Promoting Cultural Self-confidence}

Scholar Yu Qiuyu ever pointed out that, "cultures are a kind of "accumulation" over time", but it is also necessary to change existing prevailing habits and customs. In this dynamic process, a kind of "collective personalities" is developed progressively [12]. Since education about jewelry design differs from arts, people must not be too arrogant, but have to satisfy certain needs of the general public. Design education is a dynamic process, through which teachers, as subjects of education, are supposed to culturally penetrate into different parts of teaching in four dimensions, namely ecological communities, spiritual value, lifestyles and collective personalities. On one hand, students are required to explore and analyze meanings and purposes of designs as well as roles and social responsibilities of designers; on the other hand, more efforts shall be made to guide students to realize that cultures are shared among groups, their common spiritual value shall be recognized by all individuals and develop cultural self-confidence based on cultural identity. Cultural self-consciousness contributes to diverse design ideas. When they step into a society, students will have their cultural aesthetics concentrated on their works. Apart from improving design thinking of enterprises, aesthetic cultures shall be spread in the society, to which more cultural and spiritual products shall be input to gradually impact aesthetics of the general public and enhance artistic/cultural literacy of the whole nation for the final purpose of promoting overall coordination and sustainable development of the society. While enhancing personal cultural construction, people will turn into positive energy of the society and thus naturally develop cultural self-confidence.

Cultural self-consciousness is a requirement of an era. No matter in China or other countries of the world, all nations are supposed to highly recognize their own cultures, as only in this way can diverse cultures of the world coexist, complement each other and develop together. [9]
IV. WAYS FOR DEVELOPING CULTURAL SELFCONSCIOUSNESS IN EDUCATION ON JEWELRY DESIGN

Having developed for 5,000 years, Chinese cultures are rich and extensive. Plenty of folk crafts, traditions and cultures are going to be extinct. As a result, it is extremely hard to make systematic and extensive inheritance possible. Nevertheless, it is of great significance for developing contemporary cultures by protecting and inheriting this kind of intangible cultural heritages. In universities, jewelry education may be delivered from the perspective of local cultures and folk crafts to play their roles in inheriting cultural heritages based on its extraordinary education models, design ideas and works.

\section{A. Integration with Local Cultures}

In contemporary jewelry education of Chinese universities, cultural heritages may be inherited by utilizing regional resources. For instance, Suzhou embroidery, a traditional craft of Suzhou, which has been listed as intangible heritage, has developed into a unique regional craft of Jiangsu Province owing to its advantages in resources and some security technologies. These crafts may be particularly learnt and inherited through professional jewelry programs of local universities so that cultural inheritance can be cost-effective and inefficient. Liu Mingyu, who comes from Nanjing University of the Arts, integrates Suzhou embroidery with silver in necklace design. With overall succinct elegant styles and reasonable structures, the necklace looks modern, as shown in "Fig. 2". The plum blossoms on the Suzhou embroidery of the pendant and tassel ornaments just reveal the designer's great respect and recognition of traditional cultures. As shown in "Fig. 3", it is a cherry brooch creatively designed by the IFA Paris, Shanghai University of Engineering Science. Completed in combination with the craft of "relief", which is an intangible cultural heritage of Gucun, Shanghai, corresponds to the theme of the Cherry Blossom Festival in the Gucun Park of Shanghai, this design has inherited local cultures imparted in design education of universities with pure handicrafts.

In addition, local universities may cooperatively perform some projects with folk organizations to effectively support 
art exchanges, theoretical seminars, database creation, publication of materials, hosting of exhibitions for cultural heritages and participation in new product development.

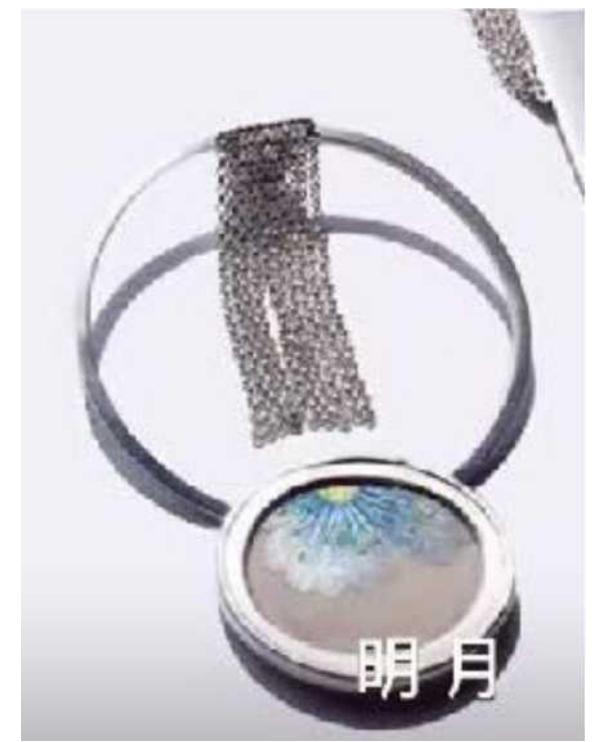

Fig. 2. Liu Mingyue's necklace with suzhou embroidery.

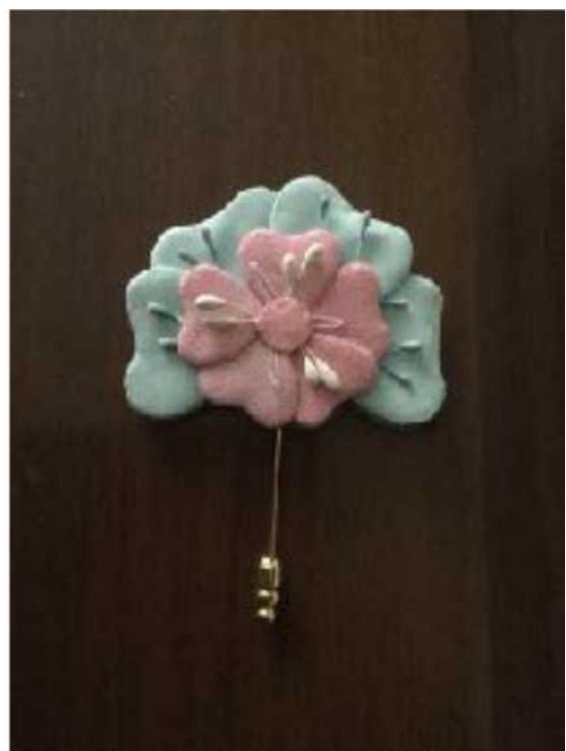

Fig. 3. Cherry Brooch made by relief.

\section{B. Integration with Folk Crafts}

There are numerous traditional Chinese craft. In an era when mechanization and industrialization are not popularized, folk crafts have spiritual and cultural life reflected from jewelry designs. In contemporary times, folk crafts are inferior in market competitions and even eliminated due to their poor efficiency and high labor costs. Nevertheless, the most primitive manual tools have been retained and preserved by the School of Jewelry, Birmingham City University, which teaches the oldest cuttlefish casting by virtue of pure hand-making [1]. While imparting handmade crafts, students are also enabled to intuitively observe and experience jewelry, crafts, tools, equipment and process of making. In this process, abstract cultural concepts are decomposed into each part of teaching. In contemporary Chinese courses about jewelry design, traditional crafts such as lacquer arts, metal filigrees, woven silk/embroidery, enamel and kingfisher are integrated and further utilized. In this process, students can feel traditional cultures and have them embodied in works, as shown in "Fig. 4" and "Fig. 5". Folk crafts are not only ethnic, but also modern. As a development path for folk crafts, integrating traditional crafts and arts with modern sciences and technologies is also a social responsibility of universities for jewelry education.

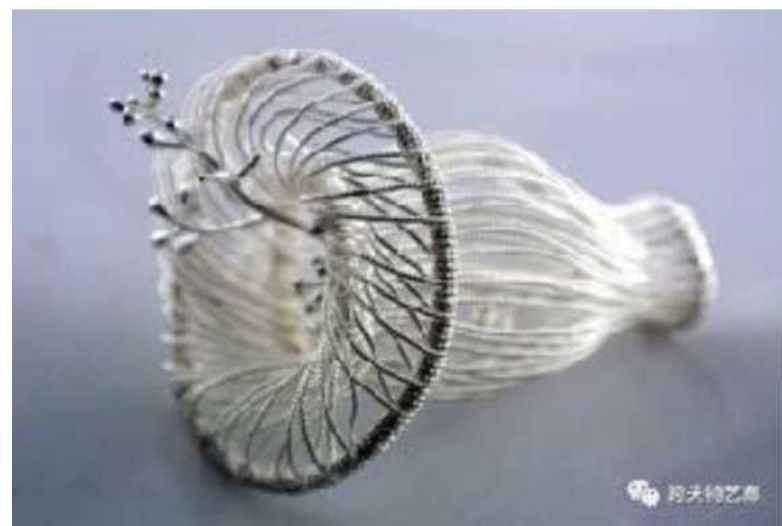

Fig. 4. A silver ornament made by designer yan ruyu with filigree crafts[13].

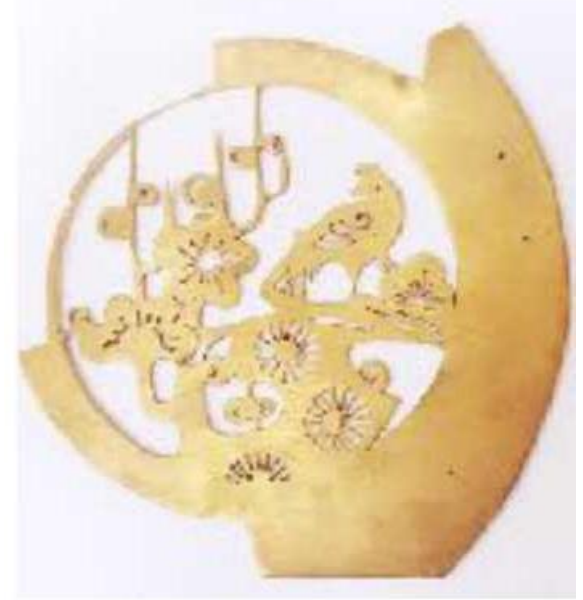

Fig. 5. Folk crafts that embodied in works.

\section{Education Models: Carriers for Inheriting Cultural Heritages}

For jewelry programs, Chinese universities mostly carry forward a teaching model for combining studios with projects, advocating that designs are for production and living. Design ideas are transformed into realistic products and the degree of their practices is enhanced theoretically. Placing an emphasis upon practices and manual dexterity, such curriculum setting can coincidentally achieve equally satisfactory results as master-apprentice models with varying methods. In drafting training plans for jewelry design, courses or internship plans about inheritance of some cultural 
heritages may be taken into account, in order to create opportunities for inheriting these cultural heritages while broadening students' horizons [14]. When they work as interns or collect folk custom, students must discover and foresee ethnic and social creative elements. Then, arrangements may be consciously made to investigate and explore local intangible cultural heritages, so that students may not only closely approach local artistic forms while reducing costs for collect folk custom, but also sort out and recreate these endangered artistic forms through teaching forces of universities.

Folk crafts are a kind of ways for jewelry designers to perceive cultures, which has been demonstrated by the fact that contemporary education about jewelry design lays an emphasis upon crafts. Brazil was the first country that introduced courses of jewelry design in Latin America. For instance, in the private Catholic University of Rio de Janeiro, there are 360 hours of professional courses and 80 credit hours of metal practices for courses of jewelry design. As supervisor of teachers, Claudio Magalhaes thinks that only if such an amount of credit hours is assigned to courses can a solid foundation be laid for crafts of metal jewelry. Besides, an adequate amount of credit hours is quite necessary. "With the development in an era, there will be a growing amount of innovative design methods and students will design in unprecedented manners, whereas solid knowledge about basic metal crafts must be acquired whatever the changes [15]". Likewise, the Art and Design School, the University of New South Wales, Australia, places great emphasis upon making metal jewelry with the most primitive hand-making crafts. Despite complete functions of present jewelry processing equipment, only by repeated exercises can feel, skills and perception about metals be improved.

\section{CONCLUSION}

Above all, cultural self-consciousness is deeply rooted in education and universities bear major social responsibilities for cultural inheritance in delivering design education. Scholar Ma Weidu ever said that, "happiness in cultures is the ultimate." Only if all individuals understand and recognize their own cultures can cultural self-consciousness be developed among groups. Higher education stimulates students' cognition and recognition of their own cultures, in order that they may develop self-consciousness, enhance their cultural self-consciousness and foster cultural selfconfidence, thus facilitating their nations' construction of strong cultural powers and strengthening cultural soft power.

\section{REFERENCES}

[1] Gong Shijun. Research on the Responsibility of Jewelry Design Education [J]. Shanghai Arts and Crafts, 2017 (3): 49-51.

[2] Dictionary Editing Office of Institute of Linguistics, Chinese Academy of Social Sciences. Modern Chinese Dictionary: Revised [M]. Beijing: Commercial Printing Hall, 1997: 1318.

[3] Yu Qiuyu. What is Culture[M]. Wuhan: Changjiang Literature and Art Publishing House, 2012.

[4] Huntington Harrison. The important role of culture [M]. Beijing: Xinhua Publishing House, 2002: 3.
[5] Edward Burnett Tylor. Primitive Culture[M].Berlin:Nabu Press, 1871:1.

[6] Tibetan Mage. Da Cheng Yi Zhang: Volume 20 [G]. Beijing: China Bookstore, 2009 (25): 402.

[7] Hou Yiangxiang. Interpretation of "Cultural Consciousness"[J]. Journal of Guizhou University (Art Version), 2017,(5th).

[8] Li Zhengtao. Reconstruction of Teachers' Spiritual World [M]. Shanghai: East China Normal University Press, 2014.

[9] Huang Yan Chinese Culture Research Center. Fei Xiaotong's thesis and cultural consciousness [M]. Beijing: Qunyan Publishing House, 2005: 2.

[10] Chen Baogui. Teacher's Cultural Consciousness [J]. Cultural Construction, 2017(24): 7.

[11] Ma Jia. In the past - appreciation of the professional exchange exhibition of the Central Academy of Fine Arts and the Sydney Museum of Fine Arts [J]. Chinese Gold Jewellery, 2007: 68.

[12] Luo Li. Jewelry Design Education: Cultural Consciousness and Status [J]. Art Education, 2013(9):181,182.

[13] Yin Yueyue. "Yearbook" exhibition artist: Yan Ruyu [J]. Inter-art Gallery, 2018-3-14.

[14] Wang Xiaotong. jewelry design education and inheritance of intangible cultural heritage[J]. Art Education, 2012(10):179.

[15] Randi Molofsky. Focus on Brazil: A firsthand Look at Jewelry Education, Technology[J]. National Jeweler, 2001(45):20. 